of smoking in the various populations could affect birth weight differently from mortality.

Finally, there remains the problem of "causation." Yerushalmy (1964, 1971) suggested that smoking is simply an index of a certain type of mother who also tends to have babies of lower than average birth weight. Some relevant facts emerge from the present data. The finding that a change in maternal smoking habits during pregnancy had the effect of putting the baby into a birth weight and perinatal mortality category associated with the new smoking habits points towards some kind of cause-effect relationship and is not compatible with Yerushalmy's hypothesis. This finding is further strengthened by the birth weight analysis which shows that the diminution in birth weight of the offspring of smoking mothers persists and is indeed little changed when allowance has been made for a number of other social and obstetric mediating factors.

These results would seem to have important implications for health education. If we assume that the difference in perinatal mortality between smokers and non-smokers in the U.K. has remained constant and that at least $30 \%$ of women currently smoke regularly after the fourth month of pregnancy, an estimate can be made of the potential saving in newborn lives per year if all these women could be persuaded to stop smoking during pregnancy. With the present (1970) overall live fetal and neonatal mortality rates, this might amount to a saving of approximately 1,500 babies each year in England, Scotland, and Wales. If a campaign were mounted along these lines it should also be possible to monitor the effects of such a campaign on birth weight and mortality rates, and thus provide a test of the causal hypothesis.

We should like to express our thanks to the Executive Committee of the National Birthday Trust for permission to use these data, and to Dr. E. D. Alberman and Mr. M. J. R. Healy for their helpful comments. This work was partly supported by a grant from the Nuffield Foundation to the Department of Growth and Development, at the Institute of Child Health, and also by a grant from the Health Education Council.

\section{References}

Butler, N. R., and Alberman, E. D. (1969). Perinatal Problems. Edinburgh, Livingstone.

Butler, N. R., and Bonham, D. G. (1963). Perinatal Mortality. Edinburgh, Ningstone.

Cornfield, J, and Haenszel, W. (1960). Fournal of Chronic Diseases, 11, 523 Davie, R., Butler, N. R., and Goldstein, H. (1972). From Birth to Seven. London, Longmans.

Frazier, T. M., Davis, G. H., Goldstein, H., and Goldberg, I. (1961) American fournal of Obstetrics and Gynecology, 81, 988.

Goldstein, H. (1971). Human Biology, 43, 92.

Rantakallio, P. (1969). Acta Paediatrica Scandinavica, Suppl. No. 193.

Roberts, C. J. (1969). Medicine Today and Tomorrow, 3, 50.

Simpson, W. J. (1957). American fournal of Obstetrics and Gynecology, 73, 808.

Underwood, P. B., Kesler, K. F., O'Lane, J. M., and Callagan, D. A. (1969) Obstetrics and Gynecology, 29, 1. Yerushalmy, J. (1964). American Fournal of Obstetrics and Gynecology, 88,
505.

Yerushalmy, J. (1971). American fournal of Epidemiology, 93, 443.

\title{
Possible Role of Malaria in the Aetiology of the Nephrotic Syndrome in Nairobi
}

\author{
P. H. REES, R. D. BARR, P. E. CORDY, A. VOLLER
}

British Medical fournal, 1972, 2, 130-131

\section{Summary}

In a study in Nairobi, Kenya, 30 young adults with nephrotic syndrome were investigated in detail and a further 18 were studied less completely. In no case was evidence found to support a possible role for malaria in the aetiology of the syndrome.

\section{Introduction}

The nephrotic syndrome is generally held to be more common in the tropics than in temperate climates. A major reason for this has been thought to be the role of quartan malaria, especially in children (Gilles and Hendrickse, 1963). In Uganda quartan malaria has been implicated as an important aetiological factor in the nephrotic syndrome not only in children but also in adults (Kibukamusoke, Hutt, and Wilks, 1967).

No physician could work in Nairobi for long without being impressed by the number of adults presenting with the nephrotic syndrome. In investigating this syndrome it was thought sensible, in view of the findings in neighbouring Uganda, to consider among other things the possible role of quartan malaria.

Department of Medicine, University of Nairobi, Nairobi

P. H. REES, M.B., B.CHIR., M.R.C.P., Senior Lecturer

R. D. BARR, M.B., CH.B., M.R.C.P., Lecturer

P. E. CORDY, M.D., Assistant Lecturer

Department of Clinical Tropical Medicine, London School of Hygiene and Tropical Medicine, London W.1

A. VOLLER, D.sc., Senior Lecturer

\section{Methods and Subjects}

A total of 48 consecutive adult patients with the nephrotic syndrome who were seen by us during a 12-month period at the Kenyatta National Hospital, Nairobi, were included in the study. The diagnosis of the nephrotic syndrome was established by means of the usual criteria (Barr et al., 1972).

The possible role of malaria was investigated in three ways. (1) Detailed histories were taken with special reference to residence in a malarious area and to previous illness suggestive of malaria. (2) Thick and thin blood films taken on 10 separate days were searched for malaria parasites. (3) Malaria antibody titres were estimated by using an indirect fluorescent antibody technique with Plasmodium falciparum as antigen. This antigen cross-reacts to some extent with the other forms of human malaria. As a precaution 21 sera were also tested with a $P l$. malariae antigen. On the same sample of blood serum IgG, IgM, and $\beta_{1 \mathrm{C}}$ globulin levels were also measured by standard immunological techniques.

\section{Results}

Thirty patients with the nephrotic syndrome were examined fully by these methods. Less comprehensive studies were carried out on the remaining 18 patients. Of the 30 fully investigated patients 22 were female and 8 were male. Their ages ranged from 15 to 39 years, 24 of them being aged between 15 and 25 years.

Histories.-Twenty-two of the fully investigated patients were Kikuyu and lived in the central, higher, non-malarious area of Kenya, though six of these had at some time visited an endemic area. Five came from areas of Kenya where there is seasonal transmission of malaria and three came from areas of endemic 
malaria. Sixteen thought that they had never had malaria and 11 that they might have had malaria. Three gave a more definite history of malaria; and of these patients one gave a history of tertian fever and one gave a history of quartan fever.

Blood Films.-Both the thick and the thin films from these patients were invariably negative. Not one parasite was found.

Serology.-The results of the malaria serology were also generally negative. With the $P l$. falciparum antigen 23 patients had no detectable antibody. Five had minimal titres (20 to 80 ), and it is notable that these five patients had at some time lived in an area of recognized malaria transmission. The remaining two patients had significant titres-one of 320 and one of 1,280 . Both of these patients, one a Luo and the other a M'luhya, had spent long periods in an endemic area. One of these two sera was positive at a titre of 20 when using the $\mathrm{Pl}$. malariae antigen, but the other was negative, as were the remaining 19 sera tested with this antigen.

In the group of nephrotics the mean IgG level was $788 \mathrm{mg}$ (range $320-1,920) / 100 \mathrm{ml}$. The mean IgM level was $162 \mathrm{mg}$ (range 62-320)/100 ml. The mean values for a control group of 42 Nairobi nurses were IgG 1,750 mg (range 1,140-3,300)/100 $\mathrm{ml}$ and $\mathrm{IgM} 146 \mathrm{mg}$ (range $28-280$ )/100 ml. The $\beta_{1 \mathrm{C}}$ globulin levels, with a mean of $178 \mathrm{mg}$ (range $56-254$ )/100 ml, were similar to those of the control group of nurses, who had a mean of $156 \mathrm{mg}$ (range 112-204)/100 ml.

Of the 18 patients with the nephrotic syndrome incompletely investigated none showed evidence of active malaria. No malaria parasites were found on any of the films made, and of the 16 sera that were examined all had negative or insignificant malaria antibody titres. The immunoglobulin patterns were similar to those of the group fully investigated.

\section{Discussion}

Historically the first suggestion that quartan malaria might cause a nephrotic syndrome was the demonstration of the coexistence of malaria parasitaemia with the syndrome (MansonBahr and Maybury, 1927).
More recently epidemiological and immunological evidence, reviewed by Edington and Gilles (1969), was put forward to support the concept that quartan malaria is causally related to many cases of the nephrotic syndrome in the tropics. In our series the findings were the reverse. Most of the patients came from the high central area of Kenya where quartan malaria is rarely, if ever, seen. Few gave a definite history of any previous illness resembling malaria.

The data from the blood slide examination suggest that malaria is not common in nephrotics in Nairobi. The serological tests also support this contention. The low rates of positive seroreactors contrast markedly with the findings of Kibukamusoke and Voller (1970) in quartan malaria nephrotic syndrome in Uganda.

Both IgG and IgM levels in the nephrotics were appreciably lower than other workers have found in the nephrotic syndrome in Uganda (Kibukamusoke and Voller, 1970) and in a malaria endemic area of Tanzania (Voller, Lelijveld, and Matola, 1971).

It can be concluded that the nephrotic syndrome commonly seen in Nairobi is not usually associated with malaria.

We are most grateful to Dr. J. M. D. Roberts and the staff of the Division of Insect-Borne Diseases, Nairobi, for their help with the malaria slides, to Professor W. F. M. Fulton for encouragement and advice, and to Dr. P. J. Munano, senior hospital administrator, Kenyatta National Hospital, for permission to make this report.

\section{References}

Barr, R. D., et al. (1972). British Medical fournal, 2, 131.

Edington, G. M., and Gilles, H. M. (1969). Pathology in the Tropics, p. 536.

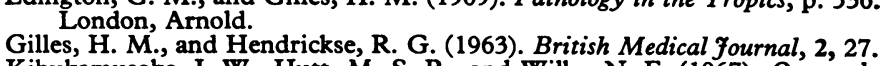

Kibukamusoke, J. W., Hutt, M. S. R., and Wilks, N. E. (1967). Quarterly Fournal of Medicine, 36, 393.

Kibukamusoke, J. W., and Voller, A. (1970). British Medical fournal, 1, 406. Manson-Bahr, P., and Maybury, L. M. (1927). Transactions of the Royal Society of Tropical Medicine and Hygiene, $21,131$.

Voller, A., Lelijveld, J., and Matola, Y. G. (1971). Fournal of Tropical Medicine and Hygiene, 74, 45.

\title{
Nephrotic Syndrome in Adult Africans in Nairobi
}

\author{
R. D. BARR, P. H. REES, P. E. CORDY, A. KUNGU, B. A. WOODGER, H. M. CAMERON
}

British Medical fournal, 1972, 2, 131-134

\section{Summary}

The adult nephrotic syndrome as met with in Nairobi is predominantly encountered in young sophisticated African women, most of whom began to use skinlightening creams containing mercury before the symptomatic onset of their illness. The particular form of mercury involved is well known to cause the nephrotic syndrome in other circumstances-for example, when applied to the skin in the treatment of psoriasis. In these circumstances the pathogenetic mechanism is thought to be of an idiosyncratic type. The use of mercurycontaining skin-lightening creams in the patients studied

University of Nairobi, P.O. Box 30588, Nairobi, Kenya

R. D. BARR, M.B., CH.B., M.R.C.P., Lecturer in Medicine

P. H. REES, M.A., M.R.C.P., Senior Lecturer in Medicine

P. E. CORDY, M.D., Assistant Lecturer in Medicine

A. KUNGU, M.B., B.S., M.R.C.PATH., Senior Lecturer in Pathology

B. A. WOODGER, M.B., CH.B., F.R.C.PATH., Senior Lecturer in Pathology H. M. CAMERON, M.D., F.R.C.PATH., Professor of Pathology seemed to be particularly associated with a "minimalchange" ("light-negative") renal glomerular lesion, this lesion being present in half of the patients. The prognosis in this group of patients seems remarkably good, with $\mathbf{5 0} \%$ entering remission, $\mathbf{7 7} \%$ of these doing so spontaneously on discontinuing the use of the creams.

\section{Introduction}

It has been alleged that Plasmodium malariae has been shown to be the cause of the African nephrotic syndrome (Kibukamusoke and Voller, 1970). No association between malaria and the nephrotic syndrome has been demonstrable in Nairobi (Rees et al., 1972). It therefore remained to define the various other aetiologies of this clinical entity in patients presenting to the Kenyatta National Hospital. We gained the impression that most of the adult nephrotics seen at this hospital were young, English-speaking, African women, and it was proposed that one factor which might distinguish this group from other patients was the use of cosmetics, and in particular skin-lightening creams. Subsequent inquiry showed that of the numerous products 